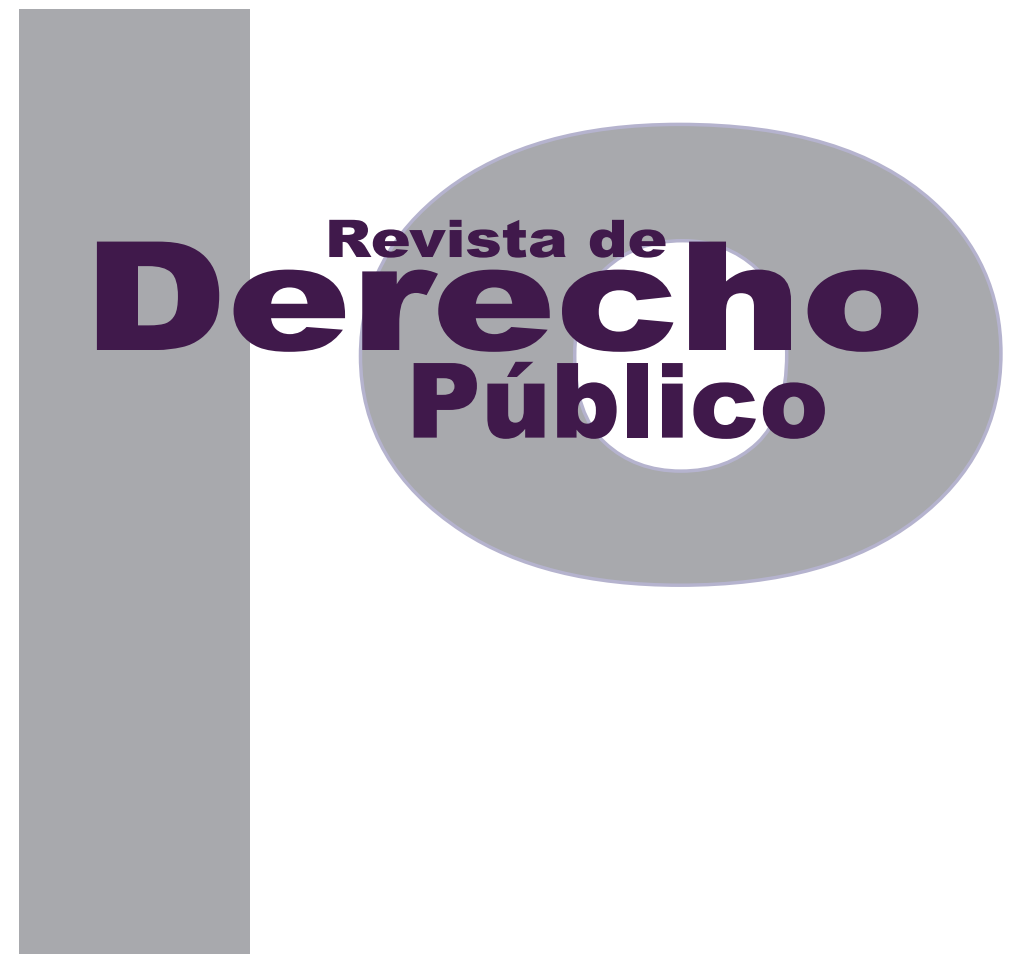

\title{
LA MESA PERMANENTE DE CONCERTACIÓN CON LOS PUEBLOS Y ORGANIZACIONES INDÍGENAS EL DIÁLOGO QUE ES SU PROPIO FIN
}

\author{
MARINA C. BRILMAN
}

Universidad de los Andes

Facultad de Derecho

Revista de Derecho Público N. ${ }^{\circ} 31$

Julio - Diciembre de 2013. ISSN 1909-7778 


\title{
La mesa permanente de concertación con los pueblos y organizaciones indígenas El diálogo que es su propio fin*
}

\author{
Marina C. Brilman**
}

ABStRACT

\begin{abstract}
RESUMEN
Este artículo busca identificar qué ocurre en Colombia en un espacio de diálogo específico: la Mesa Permanente de Concertación. Primero, se hace una breve referencia a la historia de la Mesa. Segundo, se evalúa la dinámica del diálogo entre representantes estatales e indígenas, mediante un análisis de dos sesiones de la Mesa realizadas en 2012. Tercero, se cuestiona el supuesto éxito del Decreto Ley de Víctimas 4633 de 2011. Cuarto, se identifican tres retos: delegación, representación y la institucionalización del diálogo. En conclusión, se argumenta que el diálogo en la Mesa contiene su propio fin y que, por lo tanto, su objetivo siempre ya es logrado: Ios pueblos indígenas han sido escu-
\end{abstract}

This article seeks to identify what takes place in a particular space of dialogue: the Mesa Permanente de Concertación in Colombia. First, the history of the Mesa is briefly discussed. Second, the dialogue's dynamic between State and indigenous representatives is addressed by analyzing two sessions of the Mesa in 2012 . Third, the alleged success of the Decreto Ley de Víctimas 4633 of 2011 is questioned. Fourth, three challenges are identified: delegation, representation, and the institutionalization of dialogue. In conclusion, it is argued that the dialogue taking place in the Mesa contains its own end so that its objective is always already fulfilled. Indigenous peoples have been heard, regardless

Cómo citar este artículo: Brilman, M. C. (Diciembre, 2013). La Mesa Permanente de Concertación con los pueblos y organizaciones indígenas. El diálogo que es su propio fin. Revista de Derecho Público, 31

Abogada, LL.B, LL.M (Universiteit Leiden), LL. M. (University College London), PhD (London School of Economics), profesora visitante Universidad de los Andes. Correo: brilmanm@yahoo.com. Este artículo expresa únicamente las reflexiones personales de la autora. 
chados, aún si no necesariamente se da alguna implementación a sus opiniones y sugerencias.

Palabras clave: Mesa Permanente de Concertación, pueblos indígenas, espacios de diálogo, participación, consulta. of whether any implementation is given to their opinions and suggestions.

Key words: Mesa Permanente de Concertación, indigenous peoples, spaces of dialogue, participation, consultation. 


\section{SUMARIO}

Introducción - I. LA HISTORIA Y CONSTITUCIÓN DE LA MESA - II. LA DINÁMICA DEL DIÁLOGO - DOS REUNIONES DE LA MESA EN 2012 - III. ¿EL ÉXITO DE LA MESA? EL DECRETO LEY DE VÍCTIMAS 4633 DE 2011 - IV. ALGUNOS RETOS DE LA MESA: DELEGACIÓN, REPRESENTACIÓN Y LA INSTITUCIONALIZACIÓN DEL DIÁLOGO - V. CONCLUSIONES - Bibliografía. 
¡La clave está en el diálogo! ¡La clave está en la participación y la concertación! Juan Manuel Santos El Dovio, octubre 12 de $2010^{1}$

\section{Introducción}

Las palabras citadas al comienzo de este artículo fueron expresadas por el presidente Juan Manuel Santos durante una reunión con líderes indígenas en El Dovio, Valle del Cauca, poco tiempo después de su elección a la Presidencia. Unos catorce años antes de la referida reunión, en el año 1996, mediante el Decreto 1397 se había creado un espacio de concertación integrado por funcionarios del Estado y representantes indígenas, en la forma de la Mesa Permanente de Concertación con los pueblos y organizaciones indígenas ("la Mesa”). Este artículo busca analizar qué sucede en ese espacio de concertación, por ello, aunque se hace referencia a su institucionalidad y normatividad, el objetivo es explorar cuál es la dinámica del diálogo, qué se exige, qué queda inexpresado (o tal vez solo es expresado en espacios privados), cuáles son las expectativas, y si todavía las hay.

Primero, se hace referencia a la historia de la creación de la Mesa, en el entendimiento que para poder comprender un fenómeno es necesa-

Unidad Administrativa Especial para la Reparación Integral a las Víctimas. Programa Presidencial para la Formulación de Estrategias y Acciones para el Desarrollo Integral de los Pueblos Indígenas de Colombia. Decreto Ley de Víctimas nº. 4633 de 2011. (Julio de 2012). Colección Cuadernos Legislación y Pueblos Indígenas de Colombia no. 3, p. 7. Recuperado de: http://www.vicepresidencia.gov.co/programas/Documents/Decreto4633-2011-ley-de-victimas.pdf. rio explorar porqué surgió en el momento en que lo hizo y a qué necesidad respondió (Foucault, 1976). Segundo, se busca explorar qué sucede en este espacio de concertación que, aparte de facilitar el diálogo, se llena de promesas, negociaciones, risas y suspiros resignados. Es posible que los participantes en ella no sean los actores "que hay que seguir" para entender lo que sucede en ese espacio (Latour, 1987), tal vez la dinámica del diálogo mismo sea el actor principal. Por lo tanto, es la comunicación (Luhmann, 1992), en forma de propuestas, palabras y gestos lo que se busca analizar. ${ }^{2}$ Tercero, se hace referencia brevemente al Decreto Ley de Víctimas 4633 de 2011, cuya negociación muchas veces ha sido identificada como una muestra del potencial de la Mesa como órgano de negociación y concertación. Se considera en qué exactamente consiste el éxito de la Mesa con respecto a este Decreto, y si la negociación de dicho Decreto constituye un modelo a seguir. Cuarto, se identifican tres retos principales que la Mesa actualmente enfrenta: la delegación y distribución de competencias por parte del Estado; el problema de la representación entre los miembros indígenas que hacen parte de esta y la creación de un interlocutor indígena; así como las implicaciones de la institucionalización del diálogo.

2 Luhmann, N. (1992). What is communication? Communication Theory, 2 (3), 251-259: "En sociología los conceptos de acción y comunicación [...] normalmente [...] son utilizados en referencia a un sujeto. Esto significa que los mismos asuman un autor, caracterizado como un individuo o sujeto a quien la acción o comunicación puede ser atribuido. [...] Al contrario, quisiera mantener que solo comunicación puede comunicar y que solamente dentro de tal red de comunicación lo que entendemos por acción es creada." [Traducción de la autora]. Luhmann elaboró tal concepto de comunicación, entre otros, en respuesta a la teoría de la 'acción comunicativa' de Jürgen Habermas. 
La metodología utilizada fue, primeramente, la observación de dos reuniones de la Mesa celebradas el 3 de agosto y el 25 de octubre de 2012; conversaciones informales con representantes estatales e indígenas (participantes y no participantes en las dos reuniones), antes, durante y después de estas; y el estudio de algunas publicaciones de la Organización Nacional Indígena de Colombia (onic), así como, con respecto al Decreto Ley 4633 de 2011, una publicación de agencias estatales de Colombia. Las observaciones incluidas en este artículo no pretenden ofrecer una visión completa, solo representan una impresión momentánea.

En conclusión, se argumenta que el diálogo se puede considerar 'clave', en los términos del Presidente, cuando se afirma que el diálogo es su propio fin. En tales circunstancias, el diálogo no necesariamente logra algún objetivo como, por ejemplo, el mejoramiento de la situación de los pueblos indígenas del país. Su logro es el diálogo, la participación y la concertación en sí mismas. Cuando el diálogo, dialogando, logra en ese instante su propio fin, la urgencia de alcanzar otros objetivos se disminuye. Al menos, los pueblos indígenas han participado, al menos han tenido la oportunidad de hablar y sus voces han sido escuchadas. $Y$ eso, para algunos, tal vez ya es un logro suficiente.

\section{LA HISTORIA Y CONSTITUCIÓN DE LA MESA}

En agosto de 1996, el periódico El Tiempo publicó un artículo que empezó con el siguiente texto: "Por pura malicia indígena, los representantes de 80 pueblos aborígenes de Colombia continúan la toma pacífica en la sede de la Conferencia Episcopal, en el occidente de Bogotá" (El Tiempo, 1996). ${ }^{3}$ En él se explicó que se trataba de una protesta indígena, apoyada por 16 movimientos indígenas del Chocó, Risaralda, La Guajira, Montería, Puerto Inírida, Ibagué, Pasto y el Cauca; que aunque el viernes por la noche los negociadores estatales e indígenas habían llegado a un acuerdo, los indígenas se rehusaron a salir del Episcopado hasta tanto no se firmaran los dos decretos concertados; y que mientras los negociadores trabajaban hasta tarde la noche durante la última semana de negociaciones, "Ios demás indígenas que participaban en la toma se congregaban alrededor de un televisor para no perderse detalle de los Juegos Olímpicos".

Durante la toma, la Conferencia Episcopal en un comunicado buscó clarificar su propio rol en Ios acontecimientos: "no es cierto que se hayan atropellado las personas, tampoco se ha impedido su alimentación o atención médica”. Al contrario, "con ánimo humanitario y de servicio la Presidencia de la Conferencia tomó contacto

Cfr. Caviedes Pinilla, M. (2011). Nota al pie 402: "La afirmación de la autora según la cual la 'malicia indígena es innata', revela que las viejas ideas de la década de 1920 sobre los pueblos indígenas siguen presentes incluso en los análisis académicos actuales sobre el movimiento indígena" (con referencia a González, 2010). 
con la Defensoría de los Derechos Humanos y la Cruz Roja para una atención adecuada de los indígenas". Asimismo, puntualizó que "aún si se trata de reclamos justos, el medio empleado, es decir la toma de la sede de la Conferencia, no puede ser aceptado. Se espera, por tanto, una solución pronta de la actual situación" (Conferencia Episcopal de Colombia, 1996).

Por parte de los negociadores del Estado, el viceministro del Interior expresó que "uno de los aspectos positivos de la negociación que se realiza en Bogotá es que se ha conformado un grupo de voceros indígenas con los cuales se puede concertar. A veces no era por falta de voluntad que fallaba la concertación sino porque el movimiento indígena estaba muy disgregado" (El Tiempo, 1996). Más adelante haremos referencia a la importancia de un interlocutor indígena en el diálogo tanto para el Estado como para los representantes indígenas.

Por parte de los representantes indígenas se aceptó -años después- que la movilización "se dio casi sin planearla" (onIc, 2012d), pero que ya iniciada se expandió a todo el país resultando en la ocupación de carreteras y oficinas públicas en varias regiones; que la principal razón para la movilización había sido la ocurrencia de varios actos de violencia cometidos en contra de las comunidades indígenas, así como el incumplimiento por parte del Estado de las "promesas" contenidas en la Constitución de 1991 (onic, 2012a). Al respecto, un representante indígena recuerda que en el proceso de elaboración de la Constitución de 1991 participaron dos senadores indígenas. Sin embargo, aunque el artículo 7 de la Constitución dispone que "[e]l Estado reconoce y protege la diversidad étnica y cultural de la Nación colombiana", no quedó definido cómo los derechos de los pueblos indígenas deberían ser implementados.

Los casi 45 días que duró la toma del Episcopado resultaron en la negociación y expedición de dos decretos: el Decreto 1396 creando la Comisión de Derechos Humanos y el Decreto 1397 creativo de la Comisión Nacional de Territorios Indígenas y de la Mesa Permanente de Concertación. Un representante indígena explicó que se pensaba que, con la entrada en vigor de la Constitución de 1991, ya no sería necesario lograr avances en los derechos de los pueblos indígenas "por lucha, bloqueo, [o] paro" pero que los dos decretos no fueron "aprobados por la voluntad del Estado, pero por lucha y por la organización de los pueblos indígenas" (onic, 2012a).

Antes de analizar la institucionalidad de la Mesa es importante señalar que su actividad ha variado desde su constitución en 1996. Por ejemplo, según representantes indígenas, durante la administración del expresidente Uribe Vélez celebraba reuniones cada seis u ocho meses. El 2 de noviembre de 2006, es decir, diez años después de haber sido creada, los pueblos indígenas resolvieron retirarse de todos los espacios de concertación generados por los decretos 1396 y 1397 de 1996, por la alegada falta de cumplimiento del Estado de los acuerdos pactados y porque los representantes estatales no tenían capacidad decisoria. En 2007 Colombia se abstuvo de votar la Declaración Universal de los Derechos de los Pueblos Indígenas, expedida por 
la Asamblea General de las Naciones Unidas, hecho por el cual los indígenas dejaron de asistir a las sesiones de la Mesa, las cuales fueron suspendidas por dos años (onIc, 2012d). En 2009 la Corte Constitucional declaró la inconstitucionalidad del Estatuto de Desarrollo Rural por falta de consulta previa a los pueblos indígenas. En esa y otras sentencias se hizo referencia a la función de la Mesa. ${ }^{4}$ En 2010, poco tiempo después de haber asumido la Presidencia, Juan Manuel Santos expresó su compromiso con el mejoramiento de la situación de los pueblos indígenas del país durante una reunión en la Sierra Nevada de Santa Marta con cabildos de los pueblos Kogui, Arhuaco, Kankuamo y Wiwa (El Tiempo, 2010) y las reuniones frecuentes de la Mesa fueron reinstituidas.

\section{LA DINÁMICA DEL DIÁLOGO. DOS REUNIONES DE LA MESA EN 2012}

Para poder entender la dinámica del diálogo al interior de la Mesa es necesario hacer referencia brevemente a la institucionalidad de esta. El artículo 10 del Decreto 1397 de 1996 establece su composición: son participantes permanentes por parte del Estado los representantes de nueve Ministerios y de diferentes agencias estatales,

4 Corte Constitucional de Colombia. Sentencia C-175/09, mediante la cual se declaró inexequible la Ley 1152 de 2007, "por la cual se dicta el Estatuto de Desarrollo Rural, se reforma el Instituto Colombiano de Desarrollo Rural, Incoder, y se dictan otras disposiciones." Párr. III (Demanda): "[...] los demandantes indican que contrario a lo afirmado por el Ministerio, en lo que tiene que ver con el EDR no se hizo efectivo el derecho fundamental a la consulta previa. Este hecho se comprueba, además, con el hecho que la Mesa Permanente de Concertación con los Pueblos y Organizaciones Indígenas, no haya sido convocada, en los términos del Decreto 1397 de 1996, para los fines correspondientes y descritos por la Corte en la sentencia C-030/08". entre estas, por ejemplo, el Instituto Colombiano de Desarrollo Rural (INCODER) asiste a las reuniones cuando se trata de temas relacionados con la titulación de tierras. Por parte de los pueblos indígenas participan los senadores indígenas en función en el Congreso, los exconstituyentes indígenas, un representante de la oNIc, la Organización de Pueblos Indígenas de la Amazonía Colombiana (OPIAC), un delegado de la Confederación Indígena Tairona, así como un delegado por cada una de las cinco macrorregiones (seleccionado por las organizaciones indígenas de la respectiva región ${ }^{5}$ ).

Según el Decreto 1397, el ministro del Ministerio encargado del tema que está en la agenda debe estar presente, o su representante. Algunas veces el ministro correspondiente llega más tarde, mientras un representante de este hace la introducción al tema. Anteriormente, una crítica recurrente de los representantes indígenas era que los representantes estatales no tenían competencia para tomar decisiones vinculantes para el Estado. Con respecto a los representantes indígenas cabe señalar que, actualmente, de los tres exconstituyentes indígenas solo uno participa en la Mesa, porque uno se encuentra privado de la libertad y el otro tomó la decisión de no concurrir más. Teniendo en cuenta que el Decreto 1397 no establece la posibilidad de reemplazar estos representantes, en la práctica participan solo once de los trece con derecho a asistir. En general, estos once representantes

\footnotetext{
5 Artículo 20: "[...] el Gobierno financiará los gastos que demanden las reuniones de las organizaciones por macrorregión, requeridas para su selección, previa concertación de los presupuestos en la Mesa de Concertación".
} 
son los mismos en las diferentes reuniones de la Mesa, aunque los asesores que los acompañan pueden variar.

El Decreto establece que los representantes indígenas pueden ser acompañados por asesores, ${ }^{6}$ por ejemplo, el representante de la oPIAc puede estar acompañado por un cabildo mayor de un pueblo indígena de la región. Aunque los ministerios nombrados en el Decreto siempre están presentes, los representantes por lo general varían. El Decreto establece que la Organización Internacional del Trabajo, la Comisión Interamericana de Derechos Humanos y la Conferencia Episcopal de Colombia pueden asistir a las sesiones de la Mesa. ${ }^{7}$

Según el artículo 11 del Decreto 1397, la Mesa tiene por objeto:

concertar entre éstos [los pueblos y organizaciones indígenas] y el Estado todas las decisiones administrativas y legislativas susceptibles de afectarlos, evaluar la ejecución de la política indígena del Estado, sin perjuicio de las funciones del Estado, y hacerle seguimiento al cumplimiento de los acuerdos a que allí se lleguen.

La concertación se hace por consenso, lo que explica tal vez la parálisis al momento de tomar ciertas decisiones. ${ }^{8}$ La Mesa sesiona en Bogotá, pero también es posible celebrar reuniones en

6 Artículo 10, parágrafo

7 Estos están invitados para que realicen "el seguimiento, impulso, vigilancia y divulgación al cumplimiento de las funciones de la Mesa de Concertación y de los acuerdos a que se llegue".

$8 \quad$ Artículo 17.2 "cualquier lugar del país". ${ }^{9}$ Aunque el Decreto establece que, en principio, se reúne una vez al mes, en la práctica se reúne cada dos o tres meses. Aparte existen las 'mesas hijas', así llamadas por los representantes indígenas, porque tienen la misma estructura que la Mesa pero no son públicas. En ellas se discuten temas específicos, por ejemplo, educación o salud, en preparación para la Mesa. Asimismo, existen las 'mesas hermanas' que fueron establecidas al mismo tiempo que la Mesa; se trata de la Comisión de Derechos Humanos y la Comisión Nacional de Territorios Indígenas, que también tienen la misma estructura que la Mesa.

Después de cada reunión de la Mesa, los participantes llegan a un consenso sobre los temas a discutir en la próxima reunión. La Secretaría Técnica del Ministerio del Interior, encargada de la organización de la Mesa, prepara la agenda para las reuniones; la versión final depende de la disponibilidad de los funcionarios públicos relevantes. En la agenda de la Mesa, en 2012, figuraban los siguientes temas: el Plan de Desarrollo Nacional, la reforma a las Corporaciones Autónomas Regionales, la reforma al Código de Minas y el proyecto de Ley sobre la consulta previa.

Es necesario aclarar que la Mesa, por lo general, no funciona como un foro en el cual se realizan las consultas previas a los pueblos indígenas. Solo la planificación, esto es, la llamada 'ruta metodológica' de las consultas puede ser acordada en la Mesa. A veces se trata en las reunio-

9 Artículo 17.5. Solo ha sido utilizada esta posibilidad pocas veces, aunque podría contribuir al "acercamiento" de la Mesa a las regiones (ver el párrafo sobre los retos que la Mesa enfrenta actualmente). 
nes temas que no están previstos en la agenda y que surgen en el momento. Por ejemplo, durante la reunión del 25 de octubre de 2012 el representante de la onic mencionó que el día antes un representante indígena había sido asesinado y otro -quien normalmente participaba en la Mesa- había sido detenido ilegalmente. El representante del Ministerio del Interior en ese momento llamó a la Fiscalía para acordar una cita el día después para hablar sobre el asunto.

A continuación se relatan algunos aspectos de las dos Mesas celebradas el 3 de agosto y el 25 de octubre de 2012 en distintos hoteles del centro de Bogotá. El Ministerio del Interior se encarga de la logística, elige el hotel y el menú, y compra los pasajes de los participantes indígenas que viven fuera de Bogotá. En un salón grande del hotel se ha dispuesto una mesa en forma de U, los representantes del Estado están sentados en un lado y los representantes indígenas en el otro. Las reuniones de la Mesa son públicas, excepto las discusiones que suceden antes y después de la reunión para coordinar la estrategia. Sin embargo, no hay muchas personas presentes aparte de los participantes; algunos asistentes de los representantes del Estado (entregando memorandos a sus jefes y tomando notas), algunos miembros de pueblos indígenas no participantes, y tal cual estudiante o representante de una ong.

Todos los presentes reciben jugo, café, almuerzo y un refrigerio. El rato de las comidas da lugar a comentarios en broma, pero sarcásticos, por parte de algunos representantes indígenas, como que les habían prometido manjar blanco en la reunión anterior y el Estado ni siquiera fue capaz de cumplir con esa promesa (después de haber criticado el incumplimiento por parte del Estado del Plan de Desarrollo). Tomando en cuenta que en cada reunión de la Mesa están presentes especialmente los representantes indígenas, los representantes del Ministerio del Interior y los moderadores, el ambiente es relativamente informal.

El funcionamiento de la Mesa ha sido criticado por unos y otros. Por ejemplo, indígenas no participantes han argumentado que algunas comunidades sienten que no están representadas en Bogotá y por ello los términos acordados en la Mesa (por ejemplo, con respecto a la ruta metodológica de una consulta previa sobre un proyecto en la región) pueden ser rechazados cuando se presentan a la comunidad indígena local; que el Estado a veces trata de utilizar la Mesa como el foro exclusivo para la consulta de proyectos específicos; que el Estado presenta ciertos temas de manera apurada, para que sean consultados o aprobados sin una revisión adecuada por parte de los pueblos indígenas, quienes se sienten presionados para llegar a un acuerdo. Por ejemplo, en la reunión del 25 de octubre de 2012, respecto al proyecto de ley relacionado con la reforma del Código de Minas, el representante del Ministerio de Minas y Energía explicó a la Mesa que en esa misma reunión tendrían que llegar a un acuerdo sobre la ruta metodológica, pues de no hacerlo entraría a regir una ley anterior cuyo efecto sería "mucho menos favorable" para los pueblos indígenas. Los representantes indígenas respondieron que era inaceptable que el Estado hubiera tenido 
dos años para consultar el proyecto de ley, y que -en el último momento- tratara de presionarlos para acordar la ruta metodológica sin que el proyecto de ley hubiera sido consultado todavía. Un indígena no representante en la Mesa expresó que algunos estaban considerando que habría que dejar el mecanismo de la Mesa en su totalidad si la manera de actuar del Estado no cambiaba.

Algunos representantes del Estado, por su parte, argumentaron informalmente que los representantes indígenas, a veces a propósito, parecen demorar los procedimientos y la toma de decisiones. Además, sugirieron que pareciera que algunos de ellos no asistían a las sesiones de la Mesa para representar a sus comunidades sino para beneficiarse de la comida y el alojamiento en Bogotá que reciben los participantes indígenas que no residen en la capital, según lo dispuesto por el Decreto 1397 de $1996 .{ }^{10}$

En general, los representantes del Estado muestran voluntad de discutir las propuestas de los representantes indígenas. Sin embargo, su discurso adquiere un tono más insistente y menos pacificador a medida que transcurre la mañana, llegando incluso a manifestar frustración por la falta de progreso en los temas de la reunión. Los representantes indígenas reciben las propuestas de los representantes estatales a veces con ironía, con cierta desconfianza o con

10 Artículo 17.6: "Serán dotadas por las entidades estatales que las conforman, de recursos suficientes para su funcionamiento y el cumplimiento de sus funciones y para el desplazamiento y manutención de los miembros indígenas que residen fuera de Santa Fe de Bogotá, en la medida en que dicho desplazamiento no pueda costearse con recursos provenientes de otros fondos públicos". tranquila resignación (interrumpida por algunas acusaciones sobre la falta de cumplimiento por parte del Estado de sus promesas y obligaciones). A veces, el lenguaje de los representantes indígenas se vuelve más directo. Por ejemplo, en la reunión del 25 de octubre, en que estuvo presente en la Mesa el entonces director de la Dirección de Consulta del Ministerio del Interior, un indígena relató que este había sido citado en la prensa diciendo que se sentía "entre amigos" porque estaba con representantes de grandes empresas y le preguntó cómo se sentía "ahora que está entre indios".

En la reunión del 3 de agosto los representantes indígenas indicaron que 90 de los 92 temas del Plan de Desarrollo todavía no habían sido cumplidos y que el presupuesto para cada uno de los temas tampoco había sido asignado, dando lugar a dudas sobre la seriedad y la voluntad política para implementarlo. En respuesta, el ministro del Interior sugirió discutir los diferentes temas del Plan de Desarrollo en reuniones temáticas, fuera de la Mesa, con participación de representantes indígenas y especialistas de los diferentes ministerios. Sin embargo, los representantes indígenas indicaron que tales reuniones ya habían sido realizadas, y que no querían más reuniones sino cumplimiento por parte del Estado de sus obligaciones. El ministro del Interior asistió a esta reunión, probablemente, también porque justo se dio el enfrentamiento entre el Ejército e indígenas en el Cauca. Los representantes indígenas insistieron en que el presidente Santos asistiera a la próxima Mesa. Casi dos semanas después de la referida Mesa, el Presidente se reunió con los representantes 
indígenas en el Cauca (Presidencia de la República, 2012).

En la reunión del 25 de octubre un funcionario del Ministerio de Hacienda y Crédito Público explicó que la asignación del presupuesto destinado a cada uno de los puntos incluidos en el Plan de Desarrollo era compleja, porque cada entidad del Estado tenía que dar sus comentarios sobre el presupuesto de su área de competencia. Las referencias a la competencia (o a la falta de esta) son frecuentes y parecen servir para parar las críticas de los representantes indígenas sobre el incumplimiento por parte del Estado. En esta forma, los funcionarios en vez de asumir la responsabilidad del Estado, que al final es quien debe garantizar la coordinación entre sus diferentes entidades, o de asumir la responsabilidad de una agencia estatal en un asunto particular, lo que más argumentan es que cierta "información no está disponible porque el tema es competencia de una determinada entidad". Esto conlleva parálisis en el diálogo y niega la percepción de que la estrategia de la demora es exclusiva de los representantes indígenas (mientras que los representantes del Estado si estuvieran moviéndose de manera expedita hacia un objetivo claramente identificado).

\section{III. ¿EL ÉXITO DE LA MESA? EL DECRE- TO LEY DE VÍCTIMAS 4633 DE 2011}

Después de meses de consulta previa, el 9 de diciembre de 2011 fue expedido el Decreto Ley 4633, por medio del cual "se dictan medidas de asistencia, atención, reparación integral y de restitución de derechos territoriales a las víctimas pertenecientes a los pueblos y comunidades indígenas". Elementos importantes y novedosos de este Decreto Ley son: reconocer que para los pueblos indígenas la tierra es víctima, y el carácter colectivo de los daños sufridos (incluyendo daños ambientales y culturales) así como las reparaciones correspondientes. Aunque el Decreto Ley no fue consultado en la Mesa, fue negociado en ese espacio de diálogo y su implementación tendrá que ser el resultado de un proceso de concertación en la Mesa.

La negociación del Decreto Ley en la Mesa ha sido identificada por organizaciones internacionales y nacionales como un éxito y un modelo a seguir por otros espacios de concertación, dado que muestra su potencial de concertación y la posibilidad de llegar a acuerdos tangibles entre el Estado y los pueblos indígenas. Por ejemplo, el Programa de las Naciones Unidas para el Desarrollo consideró que "se les dio a los pueblos y las comunidades indígenas un reconocimiento político como actores clave en una democracia y, al mismo tiempo, se evidenció la importancia de la consolidación de los escenarios y las metodologías de concertación y consulta" (Programa de las Naciones Unidas para el Desarrollo, 2012).

Asimismo, una investigadora del Centro de Derecho, Justicia y Sociedad describió el proceso de la negociación del Decreto Ley en la Mesa en los siguientes términos:

[l]as organizaciones indígenas de la Mesa Permanente de Concertación [...] acogerían una postura que revolucionaría -en el sentido inno- 
vador de la palabra- la forma de hacer reivindicaciones en derechos, y en sentido mecánico, el proceso mismo. Se prepararon política y jurídicamente y tomaron la iniciativa en cada paso. Presentaron las reglas de juego sobre las que cimentarían el proceso de consulta de esta norma. Los conceptos de reparación, desplazamiento, daños y otros se tejerían desde la mirada indígena (Revista Semana, s. f.).

De la misma manera, en una publicación del Decreto Ley 4633, realizada por dependencias estatales encargadas de la reparación a las víctimas y el desarrollo integral de los pueblos indígenas, la introducción se enfoca en el carácter democrático, la armonía y el reconocimiento mutuo entre el Estado y los indígenas en este proceso, así como en el diálogo “amplio y democrático" realizado en la Mesa:

Durante la gestación del decreto-ley [...], primaron actitudes conciliatorias, democráticas y dignas de todos los actores comprometidos con este proceso. Especial reconocimiento merece la decisión tomada por las autoridades indígenas al aceptar un procedimiento excepcional para la realización de la consulta previa y proponer la inclusión del artículo 205 en el proyecto de ley de víctimas, el cual le otorgó seguridad jurídica a esta Ley, preservando la adopción posterior de los decretos-ley dirigidos a los grupos étnicos del país.

Los procesos de concertación entre el Gobierno Nacional y los gobiernos indígenas, con base en el reconocimiento mutuo como autoridades políticas del Estado, son el reflejo de actitudes cada vez más democráticas y de arraigo institucional. En ese sentido, más que concentrarse en resaltar las diferencias, se buscó armo- nizar las afinidades y los intereses comunes para avanzar en acuerdos hacia la garantía de la pervivencia de los pueblos, sin que esto implique renunciar a los horizontes políticos de cada uno de los actores. En el ejercicio de esta consulta, desarrollada en el marco de la metodología concertada en la Mesa Permanente de Concertación, caracterizada por un diálogo amplio y democrático, se reflexionó, revisó y aclaró conjuntamente lo que para los pueblos indígenas ha significado el proceso de colonización y contacto con la sociedad no indígena" (Unidad Administrativa Especial, 2012).

Tomando en cuenta estos comentarios, pareciera que el éxito de la negociación del Decreto Ley 4633 constituye la realización del objetivo original de la Mesa y representa el logro para el cual esta fue establecida en 1996: el cumplimiento de su promesa y potencial. En este sentido, se podría decir que el origen del objetivo de la Mesa lo encontramos en el Decreto Ley de Víctimas 4633 de 2011 y no en el Decreto 1397 de 1996.

Sin embargo, lo que falta decir en la apreciación del Decreto Ley como una muestra de la cooperación exitosa entre el Estado y los pueblos indígenas, es que este surgió de la exclusión previa de los pueblos indígenas de la Ley de Víctimas 1448 de 2011 que no los incluyó de manera diferenciada y desconoció que el conflicto interno en Colombia se desarrolla, al menos parcialmente, en territorios indígenas. En otras palabras, el origen del Decreto Ley 4633 de 2011 es la exclusión de los indígenas de la Ley de Víctimas 1448 y, por lo tanto, de la población colombiana en general. Como dijo un líder nasa después de 
la emisión del Decreto Ley 4633: "en el tema de Ley de Víctimas, que ha recogido el tema social del país, pero ha excluido el tema indígena, hemos reivindicado que somos parte de la nación colombiana y se debe articular, pues somos la población más vulnerable. Esperamos se cumpla y se materialice (onIc, 2012b).

Asimismo, los indígenas acordaron negociar el Decreto Ley en el marco de la Mesa porque no estaban dispuestos a asumir la responsabilidad de haber obstaculizado la adopción de la Ley de Víctimas 1448 (al invocar su posible inconstitucionalidad por falta de consulta previa) para las demás víctimas del conflicto. Muy probablemente, aunque tal vez nunca fue expresado, acordaron esta ruta de negociación para prevenir ser señalados, una vez más, como los que obstaculizan el desarrollo nacional y perjudican al resto de la población. Este último argumento ha sido utilizado muchas veces por el Estado y otros actores, por ejemplo, en temas de consulta previa, y refuerza la ya existente discriminación en contra de los indígenas en general. En este sentido, mientras que el origen directo del Decreto Ley es la exclusión de los pueblos indígenas de la Ley de Víctimas 1448, el origen indirecto de éste es la discriminación. Se trata, además, de una discriminación perfecta, porque los afectados de la misma (los indígenas) la refuerzan y perpetúan por algo parecido a la autodiscriminación, o la colaboración para prevenir más discriminación.

Tal vez el origen del Decreto Ley se vuelve irrelevante cuando consideramos el resultado. Aparte de su contenido, que como notamos contiene elementos valiosos, pareciera que hasta ahora no ha sido implementado $y$, en consecuencia, difícilmente se podrá hablar de un resultado diferente al de su existencia (como suele suceder con mucha normativa en Colombia). Aunque indudablemente su expedición es un logro, representantes indígenas han identificado algunos obstáculos para la implementación, como el régimen presupuestal dispuesto para el efecto, la falta de conocimiento y difusión, y la falta de comunicación entre instituciones estatales (ONIC, 2012c).

Una consecuencia posiblemente negativa del Decreto Ley es que su negociación parece confirmar, una vez más, que excluir y discriminar no tiene mayores implicaciones, que siempre se puede. Este entendimiento se presenta en las actuales reuniones de la Mesa con respecto a otra legislación, el Código de Minas. Parece que existe la percepción de que en las discusiones, con suficiente presión, poco tiempo y haciendo uso de la amenaza implícita de la discriminación por parte de la población en general, el diálogo funcionará y finalmente se puede concertar con los indígenas.

En este sentido, se podría decir que los representantes indígenas son las víctimas del 'éxito' de la Mesa. Su colaboración favorable, aun cuando presionada, crea expectativas y confirma que así funciona el diálogo y la concertación. Todo el proceso del Decreto Ley 4633 -el origen, la negociación, la aprobación y la falta de implementación- es justificado de manera retroactiva al considerarlo un éxito y un ejemplo a seguir para cualquier concertación entre el Estado y los pueblos indígenas, desconociendo 
que este "logro" tiene su origen en la exclusión y la discriminación y que su aprobación crea las circunstancias para continuarlas. En resumen, como dijo una representante de una organización indígena, el Decreto Ley fue acordado en la manera en que fue acordado, porque los indígenas reconocieron que eso beneficiara a todos; no porque era lo deseado por ellos mismos. Después de su exclusión de la Ley de Víctimas 1448 y la falta de consulta previa, el Decreto Ley se aprobó no porque los pueblos indígenas querían; simplemente no quedaba otra.

\section{ALGUNOS RETOS DE LA MESA: DELEGACIÓN, REPRESENTACIÓN, Y LA INSTITUCIONALIZACIÓN DEL DIÁLOGO}

De las observaciones de las referidas reuniones de la Mesa y de conversaciones con representantes estatales e indígenas se identificaron algunos retos que la Mesa enfrenta actualmente. Como es imposible mencionarlos todos aquí, se identifican tres considerados especialmente importantes. El primero tiene que ver con la delegación y distribución de competencias por parte del Estado y la alegada falta de voluntad política cuando se trata del 'tema indígena'. El segundo está relacionado con la representación de los pueblos indígenas en la Mesa, concretamente con la necesidad de crear una identidad -y un interlocutor-indígena. El tercero es el diálogo mismo y las implicaciones de su institucionalización, específicamente en el caso de la Mesa.
Con respecto al primer reto, algunos representantes indígenas han anotado que uno de los problemas, tanto para la negociación como para la implementación de decisiones tomadas en la Mesa, es la falta de coordinación entre instituciones estatales; mientras algunos logran avances significativos (salud y educación), otros no (por ejemplo, en temas relacionados con tierras) (onic, 2012c). Aparte de la diferencia entre los temas en sí, y las políticas estatales correspondientes, parece que existe confusión institucional y a veces normativa, que está siendo explotada en el diálogo. Así, la responsabilidad del Ministerio del Interior, en la práctica, a veces es delegada a otras agencias estatales o ministerios, teniendo en cuenta su competencia en el tema en cuestión. A la vez, por lo menos formalmente, los representantes estatales hacen un esfuerzo por mantener las líneas institucionales claras, sobre todo para cumplir con las responsabilidades atribuidas por la normatividad aplicable y evitar invalidar las decisiones tomadas, por defectos procesales.

Asimismo, la creación de nuevas agencias estatales y los cambios en la reasignación de responsabilidades, así como las modificaciones en el marco normativo, a veces contribuyen a la parálisis del diálogo en la Mesa e impiden el cumplimiento expedito de las obligaciones a cargo del Estado. En las reuniones de la Mesa es frecuente que algún representante de un ministerio u organismo estatal informe que su entidad no tiene competencia institucional para decidir ciertos asuntos. Dichas salvedades no siempre están relacionadas con una experticia en particular; a veces son utilizadas para evitar o dene- 
gar la responsabilidad frente a una decisión que hay que tomar. Este tipo de situaciones obstaculiza la transparencia respecto a cuál entidad estatal es responsable de las deficiencias o de la no realización de los procesos acordados.

Aparte de la confusión sobre la delegación de tareas y la distribución de competencias, está la falta de recursos y su asignación a temas específicos. Otro tema que merece atención es la presencia de representantes estatales sin capacidad decisoria, aunque parece que en los últimos años ha habido más presencia de ministros en las reuniones de la Mesa. Lo antes anotado forma parte de una cuestión más general que influye en todas las discusiones: muchos representantes indígenas, y algunos estatales, tienen la impresión de que aunque se toman decisiones en la Mesa no existe una verdadera voluntad política para implementarlas. Si bien los representantes estatales aparentemente muestran voluntad para dialogar y llegar a acuerdos, los representantes indígenas piensan que se presentan de esa manera solamente para "quedar bien", que el Estado solo invita a los pueblos indígenas al diálogo cuando "necesita algo", por ejemplo, establecer la ruta metodológica para una consulta de un proyecto ley, pero no cuando son ellos quienes requieren reunirse. Un representante indígena opinó que el diálogo actualmente "se está desgastando" por incumplimiento de promesas y obligaciones por parte del Estado: “[p]or mucho que definimos, no hay voluntad política" (onIc, 2012a).

El segundo reto, como ya se dijo, está relacionado con la representación de los pueblos indí- genas en la Mesa. Al respecto es importante señalar que la OPIAC - designada como participante permanente de la Mesa en el Decreto 1397-a su vez está constituida por 36 organizaciones de pueblos indígenas y a las reuniones asiste, generalmente, el delegado de la OPIAC y dos asesores de pueblos, que normalmente varían dependiendo del tema que está en la agenda, lo que significa que la mayoría de los pueblos indígenas de Colombia tienen solo una representación indirecta: por ejemplo, el pueblo Wayuu, que es uno de los más grandes del país no tiene un representante directo en la Mesa; como forma parte de una macrorregión su vocero es un delegado de otro pueblo. Como el Decreto 1397 no dispone la posibilidad de reemplazar ni agregar participantes permanentes, la superación de este segundo reto seguramente exigirá revalorar el tema de la representación indígena para asegurar la efectividad y legitimidad de la Mesa como espacio de concertación. Aún así, el objetivo de los participantes indígenas en la Mesa es promover el "interés nacional" de los pueblos indígenas; aunque parece ser inevitable que a veces deban referirse a las regiones 0 los pueblos que representan.

Por la forma como se dispuso la representación de los pueblos indígenas en la Mesa, uno de los objetivos de la onic es la difusión de conocimiento sobre la Mesa, sus funciones y decisiones en las regiones y pueblos que no tienen representación directa en ella. Por lo tanto, algunas 'mesas hijas' que se realizan en preparación para la Mesa y sin presencia de representantes estatales funcionan a la vez como un "espacio autónomo" y un "espacio pedagógico" para explicar ciertos 
temas a los representantes que vienen de las regiones. Asimismo, el objetivo de "fortalecimiento de la Mesa" contempla el uso, por ejemplo, de las estaciones de radio regionales para difundir el trabajo de esta. Sin embargo, como dijo un representante indígena: "[n]os dan tiquetes para pasar dos días dialogando, pero no para socializar", y en el Cauca se dijo que "nos vendimos al Estado" porque nunca vieron los resultados del diálogo en la Mesa (onic, 2012a).

Lo que se busca lograr, entonces, es un equilibrio sutil entre un "acercamiento" al trabajo que se realiza en este espacio de concertación sin que la Mesa se descentralice y pierda su función como un espacio para promover el interés nacional indígena. La descentralización presentaría el riesgo, que a veces ya se está dando, según representantes indígenas, que el Estado informe a los representantes indígenas en la Mesa que ya ha llegado a un acuerdo con un pueblo en la región sobre cierto proyecto evitando así el diálogo y la negociación en esta.

Otro punto, identificado por algunos indígenas en materia de representación, es la falta de capacidad propositiva y la necesidad de mejorar el nivel técnico. Según ellos mismos reconocen "a veces las discusiones carecen de nivel técnico, carecen de datos y respuestas reales", "Ios indígenas debemos mejorar el nivel de proposición". Tal vez la poca capacidad propositiva es indicativa de la falta de una "política indígena propia", la cual, como dijo un representante indígena, "tendría que ser distinguida de una política electoral" (onic, 2012b). La percepción de ese representante es que, con la participación indígena en la Asamblea Constituyente que dio vida a la Constitución de 1991, algunos han perdido de vista la propia política indígena fundada en la cosmovisión. Asimismo, se ha dicho que esa política ha sido subordinada "a las formas convencionales del gobierno y la sociedad nacional, a través de cargos administrativos y de representación política" (Caviedes Pinilla, 2011, p. 275). Una posible consecuencia de esto sería que "[l]a discusión parece reducirse a reclamar el derecho a participar en las instituciones de decisión política y, sobre todo, administrativa, porque en el fondo, [no se defiende] un proyecto crítico del modelo de desarrollo" (Caviedes PiniIla, 2011, p. 274). ${ }^{11}$

Lo que tal vez contribuye a la falta de una política indígena propia que se percibe, es que, en opinión de algunos de sus representantes, llegan dispersos a espacios de concertación como la Mesa:

Creamos disidencias y nuevas organizaciones a las legítimas reconocidas por las autoridades tradicionales, pero es justo por no escuchar disidencias; las mismas organizaciones regionales han dado mal trato a sus hermanos indígenas, quienes obligados crean toldas aparte. Para que esto no siga ocurriendo las organizaciones indígenas deben orientar y escuchar a los hermanos disidentes para evitar que la estrategia del gobierno 'divide y reinarás' triunfe (onIC, 2012b).

La afirmación de una 'identidad indígena' o un 'interés nacional indígena' tal vez “oculta” las di-

11 Refiriéndose al periódico Unidad Indígena. 
visiones y debates entre los diferentes pueblos y organizaciones. Por ejemplo, se ha dicho que “[I]a Amazonía no aparece para hablar. La región andina habla por ella. Sobre la región amazónica sólo aparecen denuncias, pero nunca la voz de quienes lideran las organizaciones en esas regiones" (Caviedes Pinilla, 2011, p. 240). Independiente de si estas afirmaciones corresponden a la realidad, parece que existe cierto riesgo en la "construcción discursiva de [un] sujeto político" que es "hegemónico" (Caviedes Pinilla, 2011, p. 285) ${ }^{12}$ y que, por lo tanto, excluye diferencias entre los pueblos indígenas en vez de reconocerlas y celebrarlas.

La búsqueda de un 'interés nacional indígena', una 'política indígena propia' y, tal vez, una identidad indígena compartida, refleja el reconocimiento del posible beneficio que podrían tener, por ejemplo, para formular una resistencia colectiva a ciertas iniciativas del Estado (Caviedes Pinilla, 2011, p. 199). Asimismo, la formulación de una identidad indígena y la adopción de cierto tipo de discurso sobre reclamación de derechos (aunque en las mismas palabras del Estado) probablemente han contribuido a la "visibilidad" del "movimiento indígena" (Caviedes Pinilla, 2011, p. 279). En este sentido, la Mesa como espacio de concertación en el cual dicha identidad puede ser creada, reafirmada y ejercida, ha sido útil para algunos representantes indígenas. Sin embargo, a la vez, este espacio de concertación revela las dificultades y tensiones que necesariamente surgen en la formulación de una identidad o interés compartido.

12 Refiriéndose a Laclau y Mouffe.
Pero, no solo los representantes indígenas están interesados en la formulación de una identidad o política indígena. Las palabras del viceministro del Interior, con ocasión de la toma del Episcopado por parte de los indígenas, afirman que los negociadores estatales también apreciaban el surgimiento de una representación indígena "con la cual se puede concertar". El Estado tiene interés en la creación de un "interlocutor indígena” (Caviedes Pinilla, 2011, p. 197). ${ }^{13}$ Por ejemplo, cuando es necesario demostrar que cierta decisión ha sido consultada o que una entidad estatal ha seguido los trámites de participación requeridos por una normativa relevante. Se podría decir que los representantes tanto estatales como indígenas negocian esta identidad y política indígena en la Mesa, así sea implícitamente; los primeros para legitimar sus proyectos y decisiones mostrando su buena voluntad con respecto al 'tema indígena' y los segundos para promover un programa político y social. En consecuencia, se puede apreciar que la Mesa es un escenario en el cual los participantes buscan promover, a veces aparentemente, similares proyectos pero con diferentes motivos.

El tercer reto se trata del diálogo en sí mismo. La "institucionalización del diálogo" -aconsejada por la Comisión de Expertos en la Aplicación de Convenios y Recomendaciones -CEACR- de la OIT (2007, párr. 3) $)^{14}$ - entre los representantes indígenas y estatales parece tener una conno-

13 Caviedes Pinilla argumenta que esto forma parte de una política "neoindigenista" del Estado.

14 Referido a la consulta como un instrumento para institucionalizar el diálogo con los pueblos indígenas. 
tación intrínsecamente positiva, en el sentido que asegura una comunicación continua, o un "diálogo permanente" (oNIC, 2012d) entre los miembros de la Mesa. Esto, a su vez, prevendría la exclusión de los indígenas de espacios en los cuales se toman decisiones que les afectan. Sin embargo, la "institucionalización del diálogo" también puede conllevar la solidificación de ciertos elementos presentes en, y continuados por este, que no son necesariamente todos positivos. De otra parte, el hecho de que la comunicación sea continua no significa que resulte precisamente productiva. Es más, se podría llegar a la conclusión opuesta: si el diálogo es continuo no existe ninguna urgencia de llegar a acuerdos (solo si se trata de plazos impuestos por actores 'fuera' del diálogo). En otras palabras: la proliferación de espacios de diálogo y concertación puede contribuir a la parálisis de las discusiones y a la demora en la toma de decisiones.

El diálogo institucionalizado también puede reforzar o legitimar desigualdades existentes. Al respecto, llama la atención lo que dijo un líder indígena Arhuaco sobre la Mesa: "[g]racias a estos dos decretos -1396 y 1397- tenemos espacios legales para concertar; se han dado pasos muy importantes en la medida que los indígenas podemos acercarnos a las decisiones que va a tomar el gobierno" (onIc, 2012b). En otras palabras, la Mesa es vista como un espacio informativo unilateral (del Estado hacia los pueblos), más que un escenario de negociación verdadero. Es importante señalar que cuando uno habla de "relaciones de poder" o "asimetrías de poder" (Rodríguez Garavito, 2010, p.
16) ${ }^{15}$ entre participantes, el poder es representado como una noción incompleja; parece algo -supuestamente económico, social o políticoque diferentes actores tienen (y ejercen) o no tienen (o no ejercen) en grados diferentes. Sin embargo, tal concepto oculta el poder que es creado y continuado por la dinámica del diálogo mismo (el cual no es, en sí, atribuible a uno u otro participante).

El diálogo, de por sí, construye los participantes en él; participantes participativos y comunicativos (Rodríguez Garavito, 2010). En este sentido, el diálogo se puede entender como una forma de "domesticar la resistencia indígena" (Figueroa, 2006, p. 66) ${ }^{16}$. Los representantes indígenas y estatales están conscientes de que los primeros participan y contribuyen a un espacio que a veces parece ser diseñado para persuadirlos y pacificarlos y que exige adoptar cierto tipo de discurso para poder lograr avances (Lemaitre Ripoll, 2009, pp. 346-347). Más que representar una forma progresiva de participación, la cual estaría en fuerte contraste con la exclusión de los pueblos indígenas en tiempos pasados, a veces estos espacios de concertación hacen recordar la época de la Colonia, cuando solo se les dejaba 'participar' para transferir la propiedad o permitir la explotación de sus tierras. Mientras estén dispuestos a eso el diálogo continúa y, en el mejor de los casos, sus comentarios son 'tomados en cuenta'.

15 Traducción de la autora.

16 Refiriéndose a la consulta previa. 
Como dijo un representante indígena, aunque parece paradójico, la creación de espacios de diálogo como la Mesa ha traído más distancia entre el Estado y los pueblos indígenas (ONIC, 2012a). ¿Cómo se podría explicar esa afirmación? Tal vez porque la naturaleza técnica, jurídica o presupuestaria del diálogo tiene ese efecto. Tal vez porque existe una distancia entre el diálogo que se da en la Mesa y la realidad de la vida diaria de los pueblos indígenas. Tal vez por la distancia física entre Bogotá y las 'regiones'. Sin embargo, muy probablemente, ese sentimiento de distancia es una consecuencia de que, muchas veces, el diálogo es su propio fin. En este sentido, dialogar, concertar y participar es la clave para justamente continuar de dialogar, concertar y participar.

\section{CONCLUSIONES}

En este artículo se analizó qué sucede en un espacio de concertación, específicamente en la Mesa Permanente de Concertación con los pueblos y organizaciones indígenas. El actor principal del relato fue la comunicación o la dinámica del diálogo, más que sus participantes. Se hizo referencia a la historia de la creación de la Mesa, mostrando que este espacio de diálogo nació de la acción organizada de los pueblos indígenas y de la necesidad del Estado de tener un 'interlocutor indígena' con el cual poder llegar a un acuerdo. Después de una breve explicación de los aspectos institucionales de la Mesa, con referencia al Decreto 1397 de 1996 que la creó, fueron descritas algunas discusiones que se realizaron durante dos reuniones de la Mesa en agosto y octubre de 2012. Posteriormente, se analizó brevemente el supuesto éxito más importante de esta: la negociación y aprobación del Decreto Ley 4633 de 2011. Se llegó a la conclusión que el argumento que ese Decreto Ley presenta como un modelo de concertación a seguir, desconoce que dicho Decreto Ley nació primeramente de la exclusión de los pueblos indígenas de la Ley de Víctimas 1448 de 2011 y, en segundo lugar, de una discriminación implícita. Asimismo, se argumentó que la negociación del Decreto Ley 4633 representa un precedente riesgoso si se asume que los pueblos indígenas estarán siempre dispuestos a dialogar y llegar a un acuerdo bajo esos términos.

Finalmente, fueron identificados algunos retos que la Mesa enfrenta actualmente. Primero, la delegación de tareas y la distribución de competencias por parte del Estado, creando confusión e inseguridad institucional, y a veces normativa, que parece ser utilizada para evitar responsabilidades y demorar la implementación de decisiones. Esta inseguridad, junto con la falta de asignación de presupuesto y la presencia de representantes sin capacidad decisoria, forman parte de una percibida falta de voluntad del Estado para avanzar en ciertos temas. Segundo, la representación de los pueblos indígenas en la Mesa dificulta su verdadera participación. El esfuerzo para formular una identidad indígena, una política indígena propia y un interés nacional indígena, a la vez que constituye un programa político y social de los representantes indígenas, responde a la necesidad del Estado de contar con un interlocutor indígena para acordar ciertos proyectos. La relevancia de la Mesa en 
el futuro tal vez depende del éxito que tengan los esfuerzos por 'acercar' su misión y trabajo a las regiones. Sin embargo, dicho acercamiento conlleva el riesgo de fragmentarla y descentralizarla. Tercero, se argumentó que la institucionalización del diálogo, aunque asegura la comunicación continua, conlleva la solidificación de desigualdades existentes en, y creadas por, ese diálogo. Asimismo, se observó que el 'diálogo permanente' no es necesariamente productivo.

Tomando en cuenta lo anterior, parece que el logro más importante de la Mesa es su propia existencia, que es resultado del diálogo mismo, aunque del diálogo logrado por la lucha indígena. El logro parece ser que, al menos, el Estado y los pueblos indígenas se comunican con cierta frecuencia. El diálogo es la clave para que el Estado y los indígenas sigan dialogando; de esa manera, el diálogo contiene de manera teleológica su propio fin. En consecuencia, se podría decir que el diálogo es siempre un éxito y ha logrado su objetivo: el diálogo mismo. No existe espacio para fallar; un espacio de concertación es un logro en sí (mientras que la implementación de acuerdos es, estrictamente, a la vez exterior y posterior a ese diálogo). Si la existencia del diálogo es el logro alcanzado, falta la urgencia por lograr más.

\section{Bibliografía}

Caviedes Pinilla, M. (2011). Oro a cambio de espejos: discurso hegemónico y contra-hegemónico en el movimiento indígena en Colombia 1982-1996. (Tesis doctoral). Universidad Nacional de Colombia. Recuperado de http://www.bdigital.unal.edu.co/4019/1/
Mauriciocaviedespinilla.2011.pdf.

Comisión de Expertos en la Aplicación de Convenios y Recomendaciones de la OIT CEACR. (2007). Observación adoptada en 2006. Publicada 96 ILC sesión (2007). Convenio Pueblos Indígenas y Tribales, 1989 (No. 169) - Ecuador. Recuperado de http://www.ilo.org/dyn/normlex/ en/f?p=1000:13100:0::NO::P13100_COMMENT_ID:2262661.

Conferencia Episcopal de Colombia. (6 de julio de 1996). Comunicado del Secretario General de la Conferencia Episcopal de Colombia. Recuperado de http://www.cec.org.co/ index.php?option=com_content \&view $=$ artic le\&id=543:presidencia-toma-de-la-sede-delspec\&catid=63\&ltemid=279.

Corte Constitucional. Sentencia C-175/09.

El Tiempo. (4 de agosto de 1996). Continúa la toma indígena en la Conferencia Episcopal. Recuperado de http://www.eltiempo.com/ archivo/documento/MAM-460641.

El Tiempo. (5 de agosto de 2010). Juan Manuel Santos comenzará su posesión con rito en la Sierra Nevada de Santa Marta. Recuperado de http://www.eltiempo.com/archivo/documento/CMS-7845644.

Figueroa, I. (2006). Pueblos indígenas versus petroleras: control constitucional en la resistencia. SUR. Revista Internacional de Derechos Humanos, 4, 51-81. 
Foucault, M. (1976). The will to knowledge - The History of Sexuality: 1 [La volonté de savoir, trad. R. Hurley], Londres, ReinoUnido: Penguin.

González, N. C. (2010). La política alternativa del movimiento indígena caucano. En M. Archila y N. C. González. Movimiento indígena Caucano: historia y Política. Tunja: Sello Editorial Universidad Santo Tomas.

Latour, B. (1987). Science in Action, How to FoIlow Scientists and Engineers Through Society. Cambridge, USA: Harvard University Press.

Lemaitre Ripoll, J. (2009). El derecho como conjuro. Fetichismo legal, violencia y movimientos sociales. Bogotá: Siglo del Hombre Editores, Universidad de los Andes.

Luhmann, N. (1992). What is communication? Communication Theory, 2 (3), 251-259.

Organización Nacional Indígena de Colombia. (2012a). Historia de la Mesa Permanente de Concertación. [Programa de radio].

Organización Nacional Indígena de Colombia. (2012b). Mesa Permanente de Concertación. Un escenario de discusión política y garantía de derechos. Recuperado de http://cms. onic.org.co/wp-content/uploads/2012/03/ ONIC-30-A\%C3\%B1os-Historia-EscenariosdeConcertacion-y-Resitencia_Informe-Especial.pdf.

Organización Nacional Indígena de Colombia. (2012c). Balance ONIC del Decreto ley
4633/ 2011 y la Ley de Víctimas. Recuperado dehttp://www.oidhaco.org/uploaded/ content/article/706098658.pdf.

Organización Nacional Indígena de Colombia. (2012d). Historia de los escenarios de concertación. Recuperado de http://cms.onic. org.co/2012/03/historia-de-los-escenariosde-concertacion/.

Presidencia de la República. Decreto 1397 de 1996. "Por el cual se crea la Comisión Nacional de Territorios Indígenas y la Mesa Permanente de Concertación con los pueblos y organizaciones indígenas y se dictan otras disposiciones".

Presidencia de la República. Decreto 4633 de 2011. "Por medio del cual se dictan medidas de asistencia, atención, reparación integral y de restitución de derechos territoriales a las víctimas pertenecientes a los pueblos y comunidades indígenas".

Presidencia de la República. Sistema Informativo del Gobierno. (18 de agosto de 2012). Presidente Santos califica como un paso muy importante reunión con comunidades indígenas en el Cauca. Recuperado de http:// wsp.presidencia.gov.co/Prensa/2012/Agosto/Paginas/20120818_02.aspx

Programa de las Naciones Unidas para el Desarrollo. (Noviembre-diciembre, 2012). La reparación integral de los pueblos indígenas: un enorme desafío. Revista Hechos de Paz. Recuperado de http://www.pnud.org.co/he- 
chosdepaz/65/la_reparacion_integral_de_ los_pueblos_indigenas.pdf.

Revista Semana. (s. f.). El Decreto Ley de reparaciones de pueblos Indígenas. Una nueva norma de reparaciones y restitución de derechos territoriales da un nuevo aire a los derechos de los pueblos indígenas de Colombia. Recuperado de http://m.semana.com/opinion/articulo/el-decreto-ley-reparacionespueblos-indigenas/251079-3.

Rodríguez Garavito. C.(2010). Ethnicity.gov: Global Governance, Indigenous Peoples, and the Right to Prior Consultation in Social Min- efields. Indiana Journal of Global Legal Studies, 18 (1), 1-44.

Unidad Administrativa Especial para la Reparación Integral a las Víctimas y Programa Presidencial para la Formulación de Estrategias y Acciones para el Desarrollo Integral de los Pueblos Indígenas de Colombia. (Julio, 2012). Presentación. En Decreto Ley de Víctimas $n^{\circ}$. 4633. Colección Cuadernos Legislación y Pueblos Indígenas de Colombia $n^{\circ}$. 3. Recuperado de http://www.vicepresidencia.gov.co/programas/Documents/Decreto4633-2011-ley-de-victimas.pdf 